\title{
In-Vitro Release and Pharmacokinetics of Anti-tubercle Drug Ethionamide in Healthy Male Subjects
}

\author{
Mahmood Ahmad*, Asad Ullah Madni, Muhammad Usman \\ Department of Pharmacy, the Islamia University of Bahawalpur, Pakistan-63100
}

\begin{abstract}
The aim of study was to assess the pharmacokinetics of ethionamide in the local population of healthy human subjects. Serum samples were taken from each of the selected subject at different time intervals. These samples were analyzed by using High Performance Liquid Chromatography consisting of reverse phase $\mathrm{C} 18$ column, UV detector set at $291 \mathrm{~nm}$. The mobile phase was consisted of 0.02 $\mathrm{M}$ disodium hydrogen phosphate and acetonitrile (75:25) and delivered at a rate of $1.5 \mathrm{ml} / \mathrm{min}$. The value of $\mathrm{C}_{\max }$ was found to be $1.941 \pm 1.487 \mu \mathrm{g} / \mathrm{ml}$ (mean \pm SEM) and $\mathrm{T}_{\max }$ was $1.75 \pm 1.487$ hours (mean $\pm \mathrm{SEM}$ ). The area under the curve (AUC) was $8.745 \pm 0.536$ (mean \pm SEM). The elimination half life $\left(\mathrm{t}_{1 / 2}\right)$ was found out as $1.995 \pm$ 1.157 hours (mean $\pm \mathrm{SEM}$ ). The total body clearance $(\mathrm{Cl})$ was determined as $32.591 \pm 0.298 \mathrm{ml} / \mathrm{hr} / \mathrm{kg}$ (mean \pm SEM). It was concluded that ethionamide (Ethomid ${ }^{\circledR}$ SchazooLahore, Pakistan) found in consistent with the values reported in the available literature. The study will be beneficial and valuable in designing dosage regimen for the patients on ethionamide therapy and can be utilized as guideline in accessing the bioavailability and pharmacokinetics parameters in clinical situations.
\end{abstract}

Keywords: Ethionamide (ETA); Pharmacokinetics; Serum; High performance liquid Chromatography (HPLC)

\section{Introduction}

Ethionamide is an isonicotinic acid derivative of thioamide class. It is the second line orally administered drug used in the treatment of clinical tuberculosis that has failed to respond to adequate first line therapy. Ethionamide is often combined with other anti tuberculous agents for the treatment of multidrug resistant organisms. Ethionamide is active against tubercle bacilli that are growing with in human macrophages (Auclair et al., 2001; Conte et al., 2000). It is used to cure tuberculosis, a disease that infects more than a third of the world's population (Vannelli et al., 2002). Infections caused by Mycobacterium avium intracellular complex (MAI) and drug resistant mycobacterium are increasingly common in different parts of the world and are fueled with spread of Acquired Immunodeficiency Syndrome (AIDS), as a result of this second line antimicrobial agents such as ethionamide are being used much more frequently. In-vitro, ethionamide is active against most of the Mycobacteria including, Mycobacterium tuberculi and MAI (Mycobacterium Avium Intracellulare complex) in the concentration range of $0.6-1.2 \mathrm{mg} /$ $\mathrm{L}$ while Bovine strains and $\mathrm{BCG}$ are more resistant and are inhibited only by a concentration of $5.0 \mathrm{mg} / \mathrm{L}$, thus displaying broad range of potential clinical applications (Conte et al., 2000; Rebecca et al., 1999; Harnansingh et al., 1970). Extremely, lim- ited data available in literature on the pharmacokinetics of ethionamide in healthy subjects and in patients with tuberculosis thus made such studies important to be conducted (Auclair et al., 2001).

\section{Subjects, Materials and Methods}

\section{Subjects}

Twelve healthy adult male human volunteers participated in this study. The ages of volunteers ranged from 21 to 30 years and their body weights in the range of 56-70kg. On the basis of medical history, clinical examination and laboratory investigations (hematology, blood biochemistry and urine analysis), none of the participants had any revealed medical abnormality. In addition, the included subjects had no history of hospitalization and involvement in any medical trial within twelve weeks prior to the initiation of the study, and none of them had received any regular course of drug therapy within the preceding four weeks.

Subjects were excluded from the study if they had a history of serious illness, were taking any medications (including OTC) within one week prior to the start of the study, or having a history of any kind of allergy, history of hypersensitivity to ETA, Clofazimine, Cylcoserine, Paraminosalicylic acid or pyridoxine, had donated blood within 30 days prior to the study. Written consent was obtained from the volunteers. The Pharmacy ethical committee of Faculty of Pharmacy and Alternative Medicine, the Islamia University of Bahawalpur approved the protocols of this study.

\section{In-vitro studies}

The drug formulation was tested and passed the Compendial requirements with respect to its content uniformity and weight variation. Dissolutions studies were performed in $0.1 \mathrm{~N} \mathrm{HCl}$ (Dissolution media) by placing six tablets in USP apparatus-I at $37^{\circ} \mathrm{C}$. The apparatus was adjusted at $100 \mathrm{rpm}$. Samples were then drawn at designated time intervals at 5, 15, 30 and 45 minutes and analyzed for their Ethionamide content spectrophotometrically at $290 \mathrm{~nm}$ against the dissolution medium as blank (USP-NF, 2004). Concentrations were determined with reference to a standard curve. The values are given in Table 1 and shown in Figure 1.

\footnotetext{
${ }^{*}$ Corresponding author: Mahmood Ahmad, Department of Pharmacy, the Islamia University of Bahawalpur, Pakistan-63100, E-mail: ma786786@yahoo.com
}

Received December 26, 2009; Accepted December 30, 2009; Published December 30, 2009

Citation: Ahmad M, Madni AU, Usman M (2009) In-Vitro Release and Pharmacokinetics of Anti-tubercle Drug Ethionamide in Healthy Male Subjects. J Bioanal Biomed 1: 046-049. doi:10.4172/1948-593X.1000010

Copyright: (C) 2009 Ahmad M, et al. This is an open-access article distributed under the terms of the Creative Commons Attribution License, which permits unrestricted use, distribution, and reproduction in any medium, provided the original author and source are credited.

J Bioanal Biomed 
Citation: Ahmad M, Madni AU, Usman M (2009) In-Vitro Release and Pharmacokinetics of Anti-tubercle Drug Ethionamide in Healthy Male Subjects. J Bioanal Biomed 1: 046-049. doi:10.4172/1948-593X.1000010

\begin{tabular}{|c|c|c|c|}
\hline Sr. No. & Time (min) & Percent Release & SEM \\
\hline 1 & 5 & 18 & 0.128 \\
\hline 2 & 15 & 42 & 0.249 \\
\hline 3 & 30 & 72 & 0.173 \\
\hline 4 & 45 & 99.6 & 0.194 \\
\hline
\end{tabular}

Table 1: Dissolution profile of Ethionamide tablets (ETT-011).

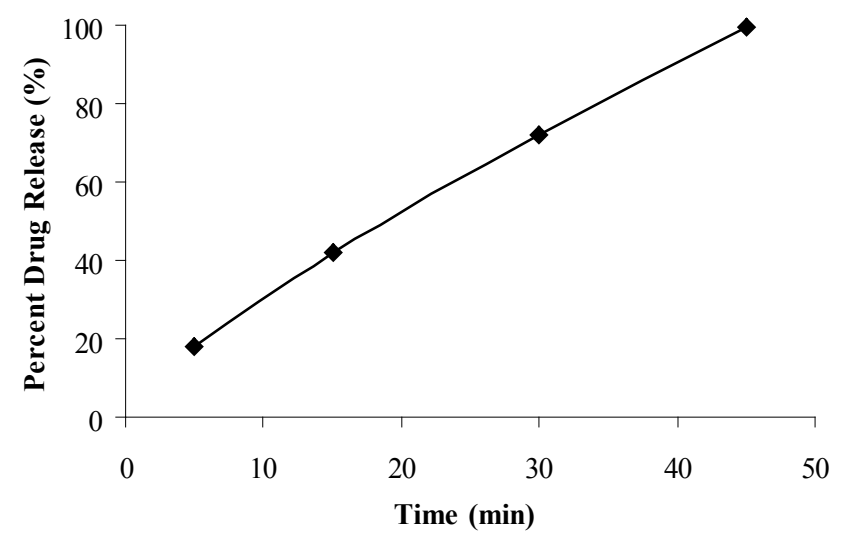

Figure 1: Percentage release of Ethionamide Tablets determined by the dissolution studies.

\section{In vivo studies}

The study was an open, single dose, complete one period of treatment dosing. Subjects received single dose of Ethionamide hydrochloride (Ethomid ${ }^{\circledR}$ Schazoo Laboratories (Pvt.) Ltd., Lahore-Pakistan) Tablets of $250 \mathrm{mg}$ (Batch No.ETT-011). Drug administration began approximately at $7.30 \mathrm{a} . \mathrm{m}$. on the study day after an overnight fast of $10 \mathrm{~h}$. Written informs consent was obtained from each subject before the study. An indwelling cannula was inserted into a forearm vein before the ingestion of Ethionamide tablet with $250 \mathrm{ml}$ of water. The subjects were asked to remain fasting for 4 hours into the study. No water was permitted 2 hours after dosing. A light breakfast was allowed at 2 hours after dosing. A light breakfast was allowed at 4 hours followed by standardized lunch and evening tea with refreshment. Cigarettes and food or beverage containing caffeine were not allowed over 24 hour.

\section{Sample collection}

A 20-gauge venous cannula was inserted into a forearm for the collection of blood samples and $3 \mathrm{ml}$ blood samples were collected through the syringe before dosing (zero time) and at $0.5,1.0,1.5,2.0,2.5,3.0,4.0,6.0,8.0,12.0$ and 24.0 hours after dosing of Ethionamide tablet. Following clot retraction, the samples were centrifuged at $4000 \mathrm{rpm}$ for $15 \mathrm{~min}$. The obtained serum was frozen at $-20^{\circ} \mathrm{C}$ pending analysis. Samples were kept refrigerated during the period of collection.

\section{High performance liquid chromatography}

Analyses were performed by using Shimadzu Liquid Chromatography, with a pump LC 10 A.S, SPD 10 A. Shimadzu U.V. Visible Detector set at $291 \mathrm{~nm}$. A reverse phase system was used consisting of a 5- $\mu \mathrm{m}$ Hypersil ODS (C18) column (250mm x $4.6 \mathrm{~mm}$ I.D.) precede by 5- $\mu \mathrm{m}$ Hypersil ODS (C18) cartridge Guard (10mm x $4.6 \mathrm{~mm}$ I.D.) column. The mobile phase was $0.02 \mathrm{M}$ disodium hydrogen phosphate buffer-Acetonitrile
(75:25), which was filtered through $0.45 \mu \mathrm{m}$ membrane filter, degassed by sonicator, and delivered at a rate of $1.5 \mathrm{ml} / \mathrm{min}$. injection of $20-\mu \mathrm{m}$ were injected, with a run time of 6 min.(Auclair et al., 2001; Charles et al., 1991).

\section{HPLC analysis}

Serum concentrations of Ethionamide were quantitated by a rapid and sensitive high performance liquid chromatographic (HPLC) method (Charles et al., 1991). The mobile phase consisted of disodium hydrogen phosphate $0.02 \mathrm{M}$ and Acetonitrile in the ratio of 75:25. 0.02 $\mathrm{M}$ disodium Hydrogen phosphate was prepared by dissolving $3.588 \mathrm{~g}$ of di sodium hydrogen phosphate in about $200 \mathrm{ml}$ of distilled water and mix thoroughly until complete solubility in distilled water, then make the volume to $1000 \mathrm{ml}$ with distilled water. Now take $750 \mathrm{ml}$ of this buffer solution and $250 \mathrm{ml}$ of Acetonitrile to make $1000 \mathrm{ml}$ with Acetonitrile. Filter the mobile phase by passing through filtration assembly under vacuum pressure of 150 -200 torr using $0.45 \mu \mathrm{m}$ membrane filter (Sartorius). Now degas the mobile phase by placing it in the sonicator for 2-3 min. until complete degassing of the mobile phase is ensured.

Stock solution $(100 \mu \mathrm{g} / \mathrm{ml})$ were prepared fresh daily by dissolving the drug in the acetonitrile. Extraction procedure was simple based on precipitation method. In the extraction procedure $1 \mathrm{ml}$ of the drug solution was spiked with $1 \mathrm{ml}$ of the blank serum in the $8 \mathrm{ml}$ glass centrifuge tube and mixes well, then centrifuge for $10 \mathrm{~min}$. Separate the upper layer (organic layer) by micropipette, filter by using of the filtration syringe and take the filtrate in $1.5 \mathrm{ml}$ eppendorf tubes. Evaporate the sample by using vacuum evaporator to dryness under the steam of nitrogen. Reconstitute the sample with $70 \mu \mathrm{L}$ of the mobile phase; vortex mix and Inject in to the HPLC injection port $20 \mu \mathrm{l}$ of the volume by injection syringe.

\section{Preparation of standard curve}

Standard curve was constructed to encompass the anticipated range of serum ethionamide concentration found in healthy Subjects. Blank serum was spiked with ethionamide drug solution to give the concentrations of $0.1,0.5,1.0,2.0,3.0$, and $4.0 \mu \mathrm{g} /$ $\mathrm{ml}$. The extraction procedure was same as described earlier. The standard curve is constructed for each of the subjects to avoid variation and to ensure precision and accuracy in the results, also average of the twelve volunteer is also calculated by taking mean of the twelve subjects.

Injections of $20 \mu \mathrm{l}$ were injected and spectra were taken of each concentration. The peak areas are noted for each concentration. The absolute recovery of ETA was $86 \%$. The within day precision $\{$ coefficient of variation $(\mathrm{CV})$ \} of validation samples was $0.42-5.26 \%$, and the overall validation precision was 0.65 3.89 pattern was determined form samples assayed over the course of study. The specificity of the HPLC assay for ethionamide was determined by testing spiked samples (Auclair et al., 2001; Charles et al., 1991).

\section{Safety Analysis}

Health assessment, including vital signs, physical examination and clinical laboratory testing was performed before and seven days after the study. Subjects were interviewed at the beginning and end of each study period and were monitored 


\section{Journal of Bioanalysis \& Biomedicine - Open Access \\ JBABM/Vol.1 Issue 1}

throughout of the confinement period to determine any adverse events potentially related to study medication of procedures (Auclair et al., 2001).

\section{Pharmacokinetic Analysis}

Pharmacokinetics analyses were performed by non-compartmental method of analysis. Maximum concentration of Ethionamide in serum $\left(\mathrm{C}_{\max }\right)$ and times to these concentrations $\left(\mathrm{T}_{\max }\right)$, area under the concentration time curve $\left(\mathrm{AUC}_{0-\infty}\right)$ and other pharmacokinetic parameters were calculated by using Kinetica Software.

\section{Results}

The in vitro results indicate that the Ethionamide formulation met the specifications for content uniformity and weight variation stipulated by compendial standards. Ethionamide concentration and peak height ratios of Ethionamide were linear throughout the concentration range of 0.1 to $4 \mu \mathrm{g} / \mathrm{ml}$. Standard curve of Ethionamide in serum was constructed to determine the slope. The limit of detection of the assay was calculated to be $10 \mathrm{ng}$ of Ethionamide per $\mathrm{ml}$ serum. Mean serum concentrations following the oral administration of Ethionamide to 12 volunteers are presented in Table 2 and plotted on rectangular co-ordinate graph $\&$ on a semi logarithmic scale in Figure 2 and Figure 3, respectively. The ration of $\mathrm{AUC}_{0-12 \mathrm{~h}} / \mathrm{AUC}_{0-\infty}$ for all individuals was $>$ 98\% indicating an adequate sampling time, since the extrapolated portion of the total AUC is less than $2 \%$. Maximum concentration in all the twelve subjects found in the range of 1.229 to $2.7527 \mu \mathrm{g} / \mathrm{ml}$ with a mean value of $1.941 \pm 1.3857 \mu \mathrm{g} / \mathrm{ml}$ at time ranging from 1 to 2.5 hours with a mean value of $1.75 \pm$ 1.487 hours.

\begin{tabular}{|c|c|c|c|}
\hline Sr. No. & Time $(\mathrm{Hrs})$ & $\begin{array}{c}\text { Concentration } \\
(\mu \mathrm{g} / \mathrm{ml})\end{array}$ & SEM \\
\hline 1 & 0 & 0.000 & 0.000 \\
\hline 2 & 0.5 & 0.671 & 0.012 \\
\hline 3 & 1 & 1.242 & 0.170 \\
\hline 4 & 1.5 & 1.603 & 0.251 \\
\hline 5 & 2 & 1.831 & 0.412 \\
\hline 6 & 2.5 & 1.299 & 0.058 \\
\hline 7 & 3 & 0.882 & 0.241 \\
\hline 8 & 4 & 0.552 & 0.321 \\
\hline 9 & 6 & 0.342 & 0.425 \\
\hline 10 & 8 & 0.276 & 0.523 \\
\hline 11 & 12 & 0.145 & 0.186 \\
\hline
\end{tabular}

Table 2: Mean \pm SEM $(n=12)$ Serum concentration of Ethionamide $\mathrm{HCl}$ administered in the oral dose of $250 \mathrm{mg}$ in Healthy Human Volunteers.

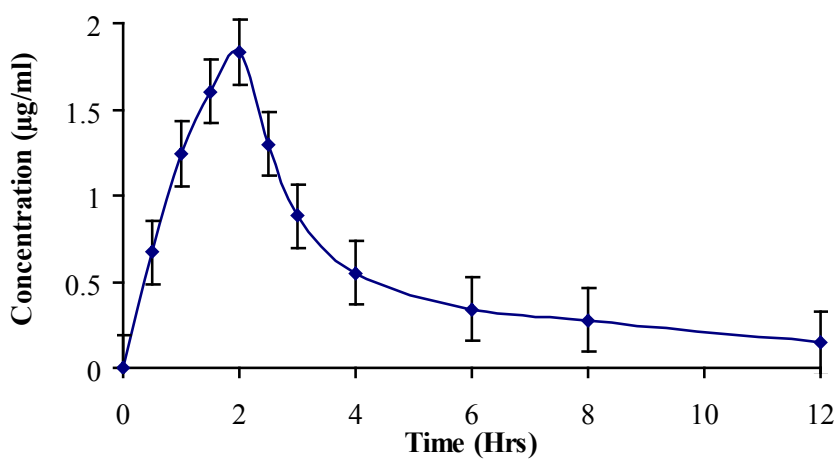

Figure 2: Serum Concentration vs time profile of Ethionamide $\mathrm{HCl}$ plotted on rectangular co-ordinate graph, administered in the oral dose of $250 \mathrm{mg}$ in healthy human volunteers $(n=12)$.

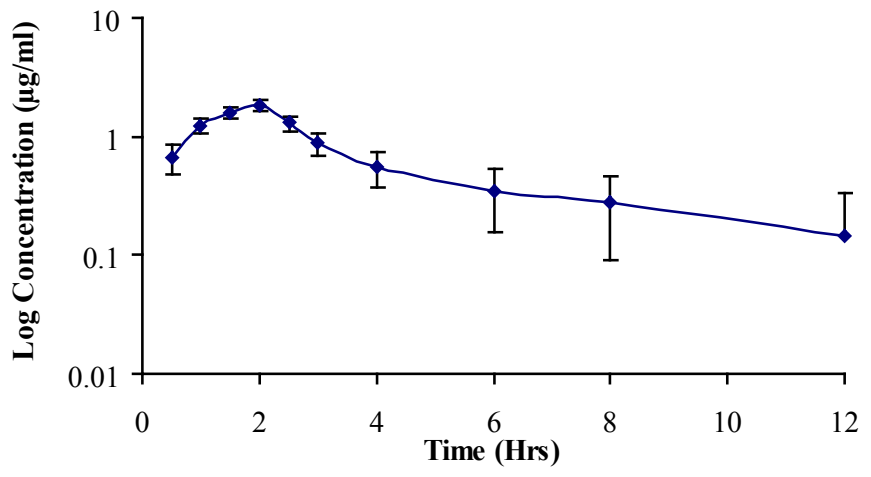

Figure 3: Concentration vs time of Ethionamide $\mathrm{HCl}$ plotted on semi-log graph, administered in the oral dose of $250 \mathrm{mg}$ in healthy human volunteers $(n=12)$.

\begin{tabular}{|l|c|c|}
\hline \multicolumn{1}{|c|}{ Parameters } & Mean value & $( \pm$ SEM) \\
\hline AUC $(\mathrm{mg} . \mathrm{hr} / \mathrm{L})$ & 8.75 & 0.5359 \\
\hline Cmax $(\mu \mathrm{g} / \mathrm{ml})$ & 1.941 & 1.3857 \\
\hline Tmax $(\mathrm{hrs})$ & 1.75 & 1.4870 \\
\hline $\mathrm{Ka}\left(\mathrm{Hr}^{-1}\right)$ & 0.384 & 3.1850 \\
\hline MAT $(\mathrm{Hrs})$ & 2.758 & 1.231 \\
\hline MRT $(\mathrm{Hrs})$ & 2.240 & 1.0954 \\
\hline $\mathrm{t}_{1 / 2}$ elimination $(\mathrm{hrs})$ & 1.995 & 1.1568 \\
\hline $\mathrm{Ke}\left(\mathrm{Hr}^{-1}\right)$ & 0.393 & 2.6268 \\
\hline Vd $(\mathrm{L})$ & 64.806 & 0.3783 \\
\hline Vss $(\mathrm{L})$ & 18.154 & 0.2958 \\
\hline Clearance $(\mathrm{L} / \mathrm{hr})$ & 32.591 & 0.2957 \\
\hline
\end{tabular}

Table 3: Pharmacokinetic and Bioavailability Parameters of Ethionamide $\mathrm{HCl}$ administered in a dose of $250 \mathrm{mg}$ in healthy human volunteers $(n=12)$.

The bioavailability and pharmacokinetic parameters of Ethionamide are calculated by using non-compartmental model of pharmacokinetic analysis for accessing $\mathrm{C}_{\max }, \mathrm{T}_{\max }$ and Area under the curve (AUC). The absorption of Ethionamide was excellent with mean serum concentration $(\mathrm{Cmax})$ of $1.941 \mu \mathrm{g} / \mathrm{ml}$ obtained at average maximum time $\left(\mathrm{T}_{\max }\right)$ of 1.75 hours. The geometric mean $( \pm$ SEM) of bioavailability and pharmacokinetic parameters $\left(\mathrm{AUC}_{0-\infty}, \mathrm{AUMC}_{0-\infty}, \mathrm{Ka}, \mathrm{t}_{1 / 2(\mathrm{abs})}, \mathrm{MAT}, \mathrm{t}_{1 / 2(\mathrm{elim})}, \mathrm{MRT}, \mathrm{Vd}\right.$ and $\mathrm{Cl}$ ) following the administration of Ethionamide are presented in Table 3 .

\section{Discussion}

Although less information is available in literature on the bioavailability and pharmacokinetics of ethionamide in healthy human subjects as well as in patients with tuberculosis. However, the bioavailability and pharmacokinetic parameters observed in this study are in accordance with the earlier reported values.

The absorption of Ethionamide is rapid and complete after oral administration and more than $90 \%$ of the given dose absorbed from gastro-intestinal tract. The absorption rate constant (Ka) in this study found in the range of 0.272 to $0.598 \mathrm{hr}^{-1}$ with a mean value of $0.384 \pm 3.185 \mathrm{hr}^{-1}$ which shows that absorption is rapid and measurable quantities of drug reaching blood with in 15 to 20 minutes. Absorption rate constant (Ka) is an important parameter having an influence on the $\mathrm{C}_{\text {max }}, \mathrm{T}_{\max }$ and AUC. Shorter the value of $\mathrm{T}_{\max }$, faster will be the absorption rate. $\mathrm{C}_{\max }$ also increases with higher values of Ka. The Mean absorption time (MAT) 1.671 to 3.554 hours $(2.758 \pm 1.23)$ shows that absorption of the drug completed within 2 to 3 hours. The maximum

Volume 1(1) : 046-049 (2009) - 048 
Citation: Ahmad M, Madni AU, Usman M (2009) In-Vitro Release and Pharmacokinetics of Anti-tubercle Drug Ethionamide in Healthy Male Subjects. J Bioanal Biomed 1: 046-049. doi:10.4172/1948-593X.1000010

plasma concentration $\mathrm{C}_{\max }$ is calculated to be in the range of 1.229 to $2.753 \mu \mathrm{g} / \mathrm{ml}(1.941 \pm 1.857)$ and the time to reach maximum concentration $\left(\mathrm{T}_{\max }\right)$ ranging from 1 to 2.5 hours. These values are in consistent with the previously reported values (Auclair et al., 2001; Zhu et al., 2002). Area under the curve (AUC) reflects the total amount of drug that reaches the systemic circulation. AUC is directly proportional to the dose of the drug. As dose of the drug increases, AUC also increases. Ethionamide is rapidly and widely distributed through out the body. The values for AUC $\infty_{\infty}$ are calculated in this study ranging from $5.231-15.615 \mu \mathrm{g} . \mathrm{h} / \mathrm{ml}$ with mean values of $8.745 \pm 0.566 \mu \mathrm{g} . \mathrm{h} / \mathrm{ml}$. This value is in accordance with the previously reported value ranging from 5.4 to $17 \mu \mathrm{g} . \mathrm{h} / \mathrm{ml}$ with a mean value of $10 \pm 0.360 \mu \mathrm{g} . \mathrm{h} / \mathrm{ml}$ (Auclair et al., 2001). The elimination rate constant (Ke) is an important parameter having effect on $\mathrm{C}_{\max }, \mathrm{T}_{\max }$ and AUC. With an increase in the elimination rate, the values of $\mathrm{C}_{\max }, \mathrm{T}_{\max }$ and AUC will decreased and vice versa. The mean \pm SEM values of elimination rate constant and elimination half life were calculated to be $0.39 \pm 2.864 \mathrm{hr}^{-1}$ and $1.8 \pm 1.362$ hours, respectively. The mean \pm SEM values reported by Zhu et al., (2001) for elimination rate constant $(\mathrm{Ke})$ and elimination half life $\left(\mathrm{t}_{1 / 2}\right)$ is $0.43 \pm 2.105 \mathrm{hr}^{-1}$ and $1.94 \pm 1.362$ hours which are in line with the present findings. The values of clearance reported in literature lies in the range of 27.5 to $66.5 \mathrm{~L} / \mathrm{hr} / \mathrm{Kg}(32 \pm 0.698 \mathrm{~L} / \mathrm{hr} / \mathrm{Kg}$, mean $\pm \mathrm{SEM})$. The clearance is a useful index for the measurement of drug removal from the body. Faster the clearance, lower will be volume of distribution and elimination half life. If elimination half life is decreased the accumulation of the drugs in the body will also decreased and the clearance will be increased. Volume of distribution is also related with the dose of the drug. As dose of the drug increases, the volume of distribution $\left(\mathrm{V}_{\mathrm{d}}\right)$ also increased. The volume of distribution $\mathrm{V}_{\mathrm{d}}$ estimated in this study ranging from 52.78 to $75.70 \mathrm{~L} / \mathrm{kg}$. Volume of distribution relates plasma concentration to the amount of drug in the body. A large value of volume of distribution shows that the drug is readily soluble and completely absorbed from the routes of administration. Volume of steady state shows the transfer of the drug from the tissue to central compartment. The volume of steady state, $\mathrm{V}_{\mathrm{ss}}$ worked out in the range of $4.128-38.388 \mathrm{~L} / \mathrm{kg}$ with mean value of $18.154 \mathrm{l} /$ $\mathrm{kg} \pm 0.2958 \mathrm{~L} / \mathrm{kg}$.

The bioavailability and pharmacokinetic parameters assessed in the present study shows a similarity with the previous reported parameters. The drug shows better absorption profile and more than $90 \%$ of the drug absorbed. The drug also shows excellent distribution and elimination profiles. These parameters will be beneficial and valuable in designing dosage regimen for the patients on ethionamide therapy and can be utilized as guideline for assessing the bioavailability and pharmacokinetic parameters in clinical situations. These studies must be conducted in the real clinical conditions in local population to determine its safety and tolerability.

\section{Acknowledgement}

The Authors wish to thank to the Management of Schazoo Laboratories (Pvt.) Ltd. Lahore-Pakistan for providing all kind facilities for the completion of this research project.

\section{References}

1. Auclair B, Nix DE, Adam RD, James GT, Peloquin CA (2001) Pharmacokinetic of ethionamide Administered under fasting conditions, or with Orange juice, Food or Antacids. Am Soc Microbiol 45: 810-814. » CrossRef » PubMed » Google Scholar

2. Charles AP, Cordon TJ, Eileen MC (1991) Improved High performance liquid chromatographic assay for the determination of ethionamide in serum. J chromatography 563: 472-475. » CrossRef » PubMed » Google Scholar

3. Charles AP, Gorden TJ, Eileen MC, Marian G (2001) Pharmacokinetic evaluation of ethionamide suppositories. Pharmacotherapy 11: 359-363. CrossRef »PubMed » Google Scholar

4. Conte JE, Golden JA, Quitty M, Kipps J, Lin ET, et al. (2000) Effects of AIDS and gender on steady-state plasma and intrapulmonary ethionamide concentrations. Antimicrob Agents Chemother 44: 1337-41. » CrossRef $»$ PubMed » Google Scholar

5. Harnansingh AMT, Eidus L (1970) Micro Method for the Determination of Ethionamide in Serum. Int J Clin Pharmacol 3: 128-131.» CrossRef » PubMed » Google Scholar

6. Malone RS, Fish DN, Spiegel DM, Childs JM, Peloquin CA (1999) The Effect of Hemodialysis on Cycloserine, Ethionamide, Para amino salicylate, Clofazimine. Clinical investigation Chest 116: 984-990. » CrossRef » PubMed » Google Scholar

7. United States Pharmacopoeia and National Formulary USP-NF (2004) United States Pharmacopoeial Convention 761. » CrossRef » PubMed » Google Scholar

8. Vannelli TA, Dykman A, Ortiz D, Montellano PR (2002) The anti-tuberculosis drug Ethionamide is activated by a flavoprotein monooxygenase. J Biol Chem 277: 12824-29. » CrossRef » PubMed » Google Scholar

9. Zhu M, Namdar R, Stambaugh JJ, Starke JR, Bulpitt AE, et al. (2002) Population pharmacokinetics of ethionamide in patients with tuberculosis. Tuberculosis 82: 91-6. » CrossRef » PubMed » Google Scholar

10.Zhu M, Nix DE, Adam RD, Childs JM, Peloquin CA (2001) Pharmacokinetics of cycloserine under fasting conditions and with high-fat meal, orange juice, and antacids. Pharmacotherapy 21: 891-7. » CrossRef » PubMed » Google Scholar 